\title{
Misconceptions of Reaction Rates on High School Level in Banjarmasin
}

\author{
Fahmi $^{1}$ and Yudha Irhasyuarna ${ }^{2}$ \\ ${ }^{1}$ Program Master of Science Education of Lambung Mangkurat University; ibnsuwandi@gmail.com \\ ${ }^{2}$ Chemical Education Studies of Lambung Mangkurat University
}

\begin{abstract}
A Research was conducted to identify students' misconceptions of class XI Science at SMAN 7 Banjarmasin on reaction rate material. The study aims to determine (1) what are misconceptions experienced by learners, and (2) determine the cause of learners' misconceptions. This study uses quantitative and qualitative descriptive design survey study. The study population were students of class XI Science at SMAN 7 Banjarmasin. The study was conducted with a purposive sampling techniques. Based on this research, misconceptions experienced by learners in grade XI Science at SMAN 7 Banjarmasin include: definition of reaction rate is the number of reactions that take place per unit of time; the reaction rate is constant because no additional concentration; high-temperature reaction rate at the beginning and then decreased because the reaction does not last long; zero order reaction means no reaction occurs; the form of the rate equation $2\left(\right.$ rate reduction $\left.\mathrm{N}_{2} \mathrm{O}_{5}\right)=\left(\right.$ rate of increase $\left.\mathrm{NO}_{2}\right)=4\left(\right.$ rate of increase $\left.\mathrm{O}_{2}\right)$ was wrong. exothermic reaction rate is faster because no heat is required; the activation energy $\left(E_{a}\right)=$ enthalpy; the concentration factor, pressure, and volume affect the rate of reaction in the reaction of the gas with the zero order; additional volume of reactants with the same concentration affect the rate of reaction; if some of the reaction compared to the speed, reaction with the highest temperature is the rate of the reaction; when the temperature is raised, the rate of the reaction towards products increased for all chemical reactions; catalysts accelerate the reaction rate and ease of collision. Misconceptions that was experienced by learners were caused by preconception or early concept of learners, learners associative thinking, humanistic thinking, reasoning incomplete/wrong, wrong intuition, the stage of cognitive development of learners, and learners' knowledge.
\end{abstract}

Keywords:learners' misconceptions, preconceptions, alternative conceptions, the reaction rate

\section{Introduction}

Learners often construct their own meaning that they see in their environment. The meaning can't be understood clearly yet based on its prior knowledge, so the meaning that learners constructed may be true or false. Errors in understanding (construction) the concept briefly can be regarded as a misconception Suyanti (2010). Another opinion also defines misconceptions as a conviction or belief that is not in accordance with generally accepted explanation and proved to be true of a phenomenon (Taylor and Kowaski, 2012).

Things that concern in the misconception are when someone knows a misconception, but he/she did not realize it was happening. It needs hard work to correct misconceptions, not only reconstruct understanding of learners (notifying is less effective), but also had to look for the causes of these misconceptions (requires detector). Teachers should be carefully and thoroughly give information (academic or non-academic), not to be ambiguous, incomplete, and give a space for misunderstanding. Therefore, it is important for teachers to understand the misconceptions first (Barke et al., 2009).

An understanding of the misconceptions can be constructed by reading some of the relevant literature, to avoid the language barrier, it is important to know the other terms of the misconceptions. Turanyi and Toth (2013) mentions some of the terms used in some of the literature that is equivalent to misconceptions, such as alternative conceptions, alternative frameworks, spontaneous knowledge and so forth. With this knowledge, it is hoped for the future that learners' misconceptions can be detected earlier and then fixed

Chemistry is a branch of science that the contents of facts, concepts, laws, theories obtained through the process and scientific analysis relating to the nature, structure, reaction, energy and material changes. Based on the statement Middlecamp and Kean in Salirawati (2010), the main study in chemistry is the concept. Most of the concepts in chemistry in the form of an abstract concept, so it is quite difficult to understand.

The reaction rate is one of the fundamental chemical materials that the discussion has not intact yet at the high school level, plus the prerequisite knowledge should be mastered quite enough consisting the nomenclature of compounds, concentration, pressure, stoichiometry, interpretation of data and other graphics. Some of them relies on the concept of dominance memory rather than reasoning, so it often makes learners get difficulty in understanding this material. The results of previous studies that show the occurrence of misconceptions among students in the study of reaction rate materials including Schmitz (2005); Cakmaci et al. (2006); Tastan and Boz (2008); Nazar et al. (2010); Sozbilir et al. (2010); Kolomuc and Tekin (2011); and Kaya and Geban (2012). So it needs a concrete solution to be done to solve the problem. 
SMAN 7 Banjarmasin is used as a benchmark of misconceptions based on the highest accreditation for the level of high schools in the city of Banjarmasin in order to show the representation of the maximum understanding of learners and minimize the identification as the result for not understanding the concept. Therefore, this research was conducted to identify learners' misconceptions in chemistry in SMAN 7 Banjarmasin, especially on the reaction rate among high school students XI Science.

Some of the assumptions and the fact this it is necessary to study to identify misconceptions students on chemistry learning, especially in the matter "reaction rate" to then do the remediation of teachers so that the study of students will be optimized.

\section{Method}

The method used in this research is the combination of quantitative and qualitative methods, the design of the research is a descriptive survey study, the research thas was conducted to determine the specific characteristics of a group Fraenkel et al. (2013). Qualitative methods in this study are characterized by their chemical interviews with teachers and students, observation of the learning process and data obtain techniques used, is purposive sampling. While quantitative methods are characterized by extracting data through written tests on selected samples subsequently tabulated and presented in the form of a percentage (Frankel et al., 2013).

The population in this study are all students of class XI Science SMAN in Banjarmasin in 2015, the samples of this study are students at SMAN 7 Banjarmasin grade XI in 2015. Subject selected by purposive sampling technique based on the consideration of the level of knowledge of learners and the quality of schools in the city of Banjarmasin. Authors consider it can provide sufficiently accurate data presentation as well as a general overview of the true extent of misconceptions in chemistry especially the material "reaction rate" that occurs among students of class XI SMA Negeri Banjarmasin.

Another consideration concerned by the researcher is to test materials that have been taught in school by teachers and then do the test afterwards. From this trial the researcher expect to obtain accurate data and clear misconceptions number of the tested material. This study uses a purposive sampling technique because the misconceptions that wanted to be observed on members of the population are intended to represent the other members of misconceptions optimally in the ability of learners constructing cognitive knowledge.

\section{Results and Discussion}

The initial step of this study is to survey some of the high schools in Banjarmasin, conducted interviews to teachers of chemistry lessons at school and learning process in the classroom. The results, showed that on some chemical materials, learners have difficulty understanding the concept as a whole, especially in the matter of reaction rates.

This is illustrated that learners opine when someone reacting a substance with other substances and did not change anything at room conditions, then both of these substances are not able to react with each other, for example the magnesium metal that does not react with cold water. The concept is wrong because the reaction can occur in other conditions, magnesium can react with hot water by the reaction: $\mathrm{Mg}(\mathrm{s})+2 \mathrm{H}_{2} \mathrm{O}(\mathrm{l}) \rightarrow \mathrm{Mg}^{2+}$ $(a q)+2 \mathrm{OH}^{-}(a q)+\mathrm{H}_{2}(\mathrm{~g})$, it's proved by the changing color of the solution after the addition of phenolphthalein indicator from clear to red which indicates the formation of the base solution.

The next step taken is testing this instrument misconceptions detector in rate of reaction. The cause of misconceptions among students traced through interviews. Based on the results of the analysis of the answers of students obtained a total percentage of misconceptions students at SMAN 7 Banjarmasin presented in Picture 1.

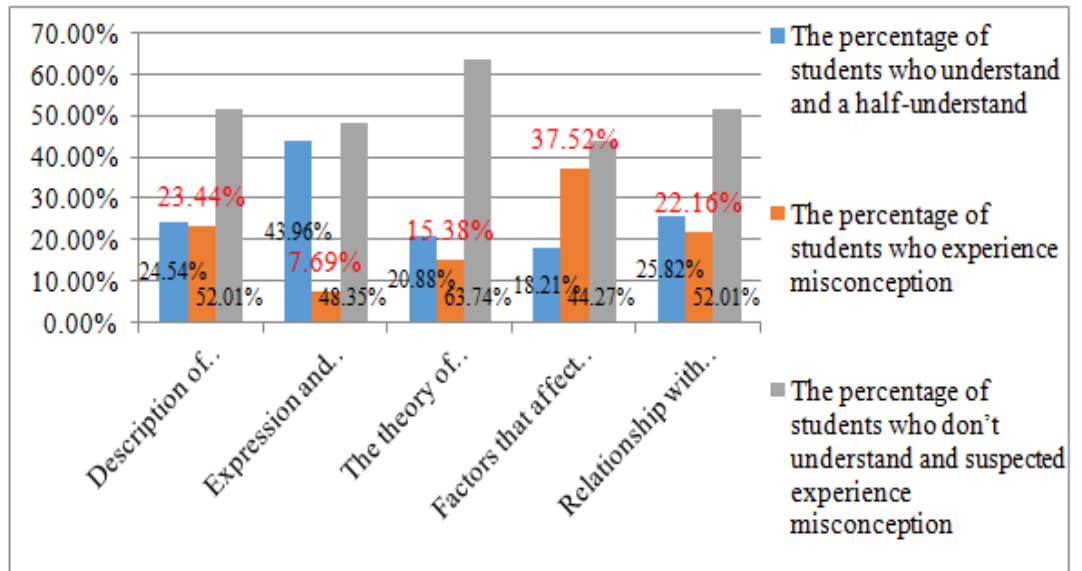

Picture 1: The percentage of learners based discussion misconceptions reaction rate 
Evidence of students experiencing misconceptions is that when students choose the correct answer but give the wrong reasons, or otherwise. This indicates there is a problem in the self-learners when they construct knowledge they acquire. The interview for learners to find out why students experiencing misconceptions in the material reaction rate was analyzed by category descriptions reaction rate, expression and determination of the rate, reaction rate theory, factors affecting the reaction rate, and the relationship of the rate, enthalpy and equilibrium.

\section{(1) Description of ReactionRate}

Misconceptions that are found on these items is "the reaction rate may not be deductible and definition of reaction rate is the number of reactions that take place per unit time". Because the definition of the rate that is often written in the book is a change in the concentration of reactants or products per unit of time or changes in unit time and also the words "rate is a measure of how fast or slow a reaction to take place" or "rate tells you how fast or how slow a process is happening".

These misconceptions are categorized by cause learners associative thinking of the word and the rate of change. Learners rarely connect the words used in the reaction rate, which is "change the number" which can be interpreted correctly for the "reduction" or "extra" components of a substance. The word number of reactions that take place frequently encountered learners, when the process of recalling the words often associated with the reaction products thus considered in line. The problem was discovered when the reaction takes place, if calculated directly will be very difficult if not impossible. Thus, the required indicator else (manual) to find out the rate of a reaction that changes the number of substances that can generally be expressed in concentration, volume or pressure.

Other misconceptions are at the beginning of the first reaction to the amount of $\mathrm{HCl}$ in the reaction is more than the result of the last reaction, causing the reaction rate increases with increasing time and then declined; the reaction rate is constant because no additional concentration, temperature; high reaction rate at the beginning and then decreases as the reaction rate and the time inversely; high reaction rate at the beginning and then decreased because the reaction does not last long; the reaction rate continues to rise because usually when the laboratory practice is surely the reaction will increase, it is very rare decline, but there are calculations if measured in time, the rate continues to rise as a result of the reaction in the form of $\mathrm{CO}_{2}(\mathrm{~g})$ because the gas the reaction rate further rate; the reaction rate decreases and then increases as the essence of the reactants progressively reduced as processed into products, but because of the reversible reaction then occurs the movement of products to reactants and of adhesiveness to the current product has an equilibrium reaction.

The errors construction are caused intuitive thinking and humanistic thoughts. Learners have successfully assumed a high concentration at the beginning, but learners experiencing misconceptions about the high concentration becomes a clue to the number of collisions that occur with a higher frequency then the initial reaction rate is higher. More learners thought that it need a warming first to make the reaction occur. They also think that product into the gas out of the system so that the possibility of a collision with a solution of the product decreases and increases the likelihood of collisions occur reactants.

Based on the number of options they choose, students think that in defining the reaction rate should not be solely concerned with one of the substances, but must be fully disclosed. They have not been able to connect a definition into mathematical form and vice versa. In addition, students are also very rarely trained to give meaning to a definition and then be led to make a rate equation, as a result they found the reaction rate can't be defined from one substance, even though it is still allowed. So they concluded the reaction rate based on the number of reactions that occur within a given time because learners are not guided to find out how to measure the rate of a reaction.

Research conducted by Fahmi (2015), found that the students understanding will form better if the students are told what is associated with a concept so that they can sense of what is learned. During this time, most students consider the definition of a thing is not too important, but if you lose the core of a definition of the word, learners will be confusion as to develop its concept. This is also consistent with the results of research Kolomuc and Tekin (2011); Kaya and Geban (2012), many learners who think the reaction rate based on the time because students are more familiar with the measurement of time than measuring changes in a concentration or amount of a substance.

\section{(2) Expression and Determination Rate}

Misconceptions found in these items is a form of rate equation 2 (the rate reduction $\mathrm{N}_{2} \mathrm{O}_{5}$ ) = (the rate of increase $\left.\mathrm{NO}_{2}\right)=4$ (the rate of increase $\mathrm{O}_{2}$ ) is wrong and zero-order reaction means no reaction occurs. This misconception occurs because of incorrect preconceptions, students think that to make the rate equation, 1 (one) divided by the coefficient of reactants equals $(=) 1$ (one) divided by the coefficient of other reactants and forwarded to the product. Zero-order reactions reacted with various concentrations do not affect the reaction 
rate, the number 0 (zero) may be associated learners as there is no change or no meaning, though the meaning is no change in speed or does not mean increasing concentration on the rate of reaction.

Based on interviews with students, the information obtained "the higher the order of the reaction occur more quickly", learners associate that with the higher the order, the greater the rate of which is directly proportional to the rank order in a rate law. This is wrong because every reaction has rate law of its own, at this level, students have not been taught yet that the order of reaction can be changed as in the enzyme reaction. Learners are minded to a discussion of the decomposition reaction of dinitrogen pentoxide, the data are not sufficient, it may be necessary enthalpy minimal (at least there enthalpy data). So they came to the conclusion to what makes the matter can't be determined. This indicates that learners are wrong, because they are more often given exercises that do not support the full conceptual understanding, so they believe more that there is an answer that is contained exactly on the options given than to say that the two things are not related. This data is supported by the results of the interview to the students, they chose order 1 in the decomposition reaction of dinitrogen pentoxide because they thought that the order is little.

These results indicate that not all students experiencing misconceptions, there are a handful of people thinking "to the decomposition reaction of dinitrogen pentoxide, the order does not determine the rate". After tracing the reason of the inability of the order is used as an indicator to compare the rate of reaction, mostly end up on the learner can't explain further (lack of knowledge). Ahiakwo and Isiguzo (2015) in their research found that in the learning of chemistry students are less likely to understand the concept as a whole. Based on this, of course, we also need to provide training to the content matter is conceptual and not predominantly about algorithmic, so that later learners are expected to connect the concept of (qualitatively) and computation (quantitatively) and forwarded in forming conclusions (generalizations) right.

In same with these results, Tastan and Boz (2008) found misconceptions about the reaction rate at zero order reaction caused at least information obtained equipping learners and lack of meaning symbolizing the pace of their learning resources.

\section{(3) The Reaction Rate Theory}

Misconceptions found in this item is an exothermic reaction needed more pace because it is not hot; more endothermic reaction rate due to the heat $\Delta H=+$ sign, then the reaction will run faster because of higher temperatures; $\mathrm{E}_{a}=$ enthalpy; reaction $\mathrm{CH}_{3} \mathrm{CHO} \rightarrow \mathrm{CH}_{3}+\mathrm{CHO}$ with $E_{a}=76 \mathrm{kkal} / \mathrm{molthe}$ largest energy, thus speeding up the reaction stages; the reaction $\mathrm{CH}_{3}+\mathrm{CH}_{3} \rightarrow \mathrm{C}_{2} \mathrm{H}_{6}$ with $E_{a}=0 \mathrm{kkal} / \mathrm{mol}$, the rate $=0 \mathrm{kkal} / \mathrm{mol}$, has no changes occurs in reaction, reaction $\mathrm{CH}_{3}+\mathrm{CH}_{3} \rightarrow \mathrm{C}_{2} \mathrm{H}_{6}$ with $E_{a}=0 \mathrm{kkal} / \mathrm{mol}$ is the slowest stage because based on the describing in the fourth reaction is $0 \mathrm{kkal} / \mathrm{mol}$; on the reaction $\mathrm{CH}_{3}+\mathrm{CH}_{3} \rightarrow \mathrm{C}_{2} \mathrm{H}_{6}$ with $\mathrm{E}_{a}$ $=0 \mathrm{kkal} / \mathrm{mol}, \mathrm{kkal} / \mathrm{mol}$ is slightly existing so there is no reaction occurred.

The cause of this misconception is the reason (reasoning) which is incomplete or incorrect generalizations, and associative thinking. Based on the interview, found many the students failed to clarify the comparison or correlation between the rate of exothermic reaction and the rate of endothermic reaction as learners who explains, "because it was hot, the rate increases, immense energy, (- energy into and + energy out)", Learners undergo reconstruction error when he calls back its knowledge that are rarely trained to be connected. This is supported by learners' the humanistic thoughts who construct their knowledge so they compared the rate of enthalpy data directly, whereas the specific reaction of course need to do the experiment first.

Contrary of this, among them also there are learners who construct that "enthalpy does not determine the rate". The term $E_{a}$ and $\Delta H$ which often occur together lead them to wrong in doing construction. Preferably in such a case is confirmed differences between them clearly so that misconceptions students may be avoided.

In line with the results of Bilgin and Geban (2006), the traditional learning which is often done in schools to make learners do not fully understand the concept of chemistry. This is supported by the results of research Kaya and Geban (2012) who found that students often fail to connect the enthalpy of the reaction rate, which may be due to very infrequently do the review that connects information between chapters such as thermochemical and reaction, even though the discussion-those topics systematization is needed in a reaction. If the exercise is done about this, learners are expected to connect more with the knowledge of other subjects, such as the discussion of equilibrium, electrochemistry, chemical calculations (stoichiometry), physical and chemical aspects related to the equation.

\section{(4) Factors Affecting Rate}

Misconceptions that are found on these items that the concentration factor, pressure, and volume affect the rate of reaction in the reaction of the gas with the order to zero; factors that affect the rate of surface area due to a physical reaction solids, has not reached the more the number of frequency of collisions that occur; the addition of solvent to the reaction rate yet to be reviewed until the collision factor; additional volume of reactants with the same concentration affect the rate of reaction; if some of the reaction compared to the speed, 
reaction with the highest temperature is the rate of the reaction; if some of the reaction compared to the speed, reaction coefficient lower load on the product is the slowest reaction; reaction known its $k$ value can't be forecasted speed because no $\Delta H$; reaction known its $k$ value can't be forecasted speed because they do not know each order of substances, and the concentration of each substance.

The cause of this misconception is the reason (reasoning) which is incomplete or incorrect generalization, intuition is wrong, humanistic thoughts, preconceptions that are not appropriate, and associative thinking learners. Things can invite these misconceptions contained in one book, that, "In reaction to ... a form of gas .... Extra pressure to decrease the volume will increase concentration, thereby increase the rate of reaction. "Although this information is true, if this information is immediately swallowed up entirely by the students, it can lead to misconceptions because they do not integrate with the discussion of equilibrium. In this case, of course it should also be added confirmation that is no information linkages between factors that influence the reaction rate by factors affecting equilibrium (pressure, volume, concentration, and reaction order).

Results of interviews with students for a discussion of collisions between atoms, if a substance is given the pressure, the reaction will be the rate, similar to the style; a volume does not affect the reaction, for example the number substances are 2 (two), wherever it put, it's still be 2 (two). Learners revealed, the assumption that a large volume will tend to cause reactions are slower, such as those in the race. Learners also construct, "if the surface is small then the reaction will be faster, and if a large surface area, the reaction will be slower. Based on the above, it was found that students were more confident the desired answer is always worth an effect or no effect at all based on the experience of learners.

Admittedly, it is difficult to explain something abstract, learners rely more on their feelings rather than facts that can be explained scientifically, but at that point we can also lure them to think, so they have the high attention by presenting difficult matters they trust so the can reconstruct the knowledge.

Another interview done on learners, "for example, one person who has large volume, he will be run slow". This indicates that learners are rarely trained to think scientifically, guided to explain phenomena they encounter with a scientific approach. Keep in mind that in order to obtain information from learners optimally, it needs to be persuasive approach so that students feel comfortable and not embarrassed express their understanding of the assortment.

This is same with the recognition somewhat reluctant learners express an opinion, because sometimes the students had two motives, the first truly do not know or do not know because of shame (fear of being wrong). Therefore, it should be emphasized to the more important that it is the reason why they responded so than their correct choice (although it is also important). The teacher's role is certainly very important to correct a little bit wrong analogy and insists that the analogy has limits so he can't be used anymore, because sometimes students are wrong in generalizing without warning from the teacher.

These result is same with research of Kariper (2014) which shows that learners do not understand the whole concept of chemical reactions. Nazar et al. (2010) in his research also found that $57.89 \%$ of students who have misconceptions regarding the effect of temperature on reaction rate with regard increase in temperature may affect the activation energy and $57.89 \%$ of students experiencing misconceptions regarding the influence of the catalyst on the rate of reaction in which learners consider the addition of a catalyst can increase the activation energy of the reactants.

This discussion is a discussion that is easy to bring misconceptions (percentage of 52.75\% was found on items that misconceptions). This is because only rarely in the explanation associated with the collision theory, the reaction energy and visuals that should help learners to understand how the characters of a reaction considered.

\section{(5) Relationship with The Rate of Reaction Equilibria and Reaction Enthalpy and Use of Catalysts}

Many misconceptions were found in the collection of these items: (1) when the temperature is raised, the rate of the reaction towards products increased for all chemical reactions; (2) any chemical reaction whose temperature is raised then the reaction rate increases; (3) an endothermic reaction is faster; (4) the rate of the reaction towards the product increases when the temperature exothermic reaction raised; (5) The reversible reaction: the rate of the forward reaction and the reverse reaction rate has a value equal; (6) a reversible reaction enthalpy equal; (7) if one of reaction is slower than others the reaction would not reversible $v 1=v 2$; (8) when the temperature is raised, the rate of reaction toward the product will increase the gas reaction because the reaction equilibrium occur only in gas and liquid; (9) the catalyst affects the reaction rate is higher $\Delta H$; (10) catalysts accelerate the reaction rate and ease of collision; (11) autocatalyst is to speed up, so the longer the time the higher the rate of reaction; (12) on reaction with autocatalyst, the reaction rate decreases because the reaction rate is inversely proportional to the time; (13) on reaction with autocatalyst, the reaction rate decreases because one product become the catalyst so that the slower pace; (14) based on the following chart, the end of the reaction occurs at the point to 1 (one) because it shows the rate of increase in the concentration; (15) the end of the reaction occurs in line 3 (three) because there has been a perfect stage process; (16) the dotted line at the 
number 4 (four) is the last line, which means indicate the end of the reaction. This can be seen from Picture 2 below:

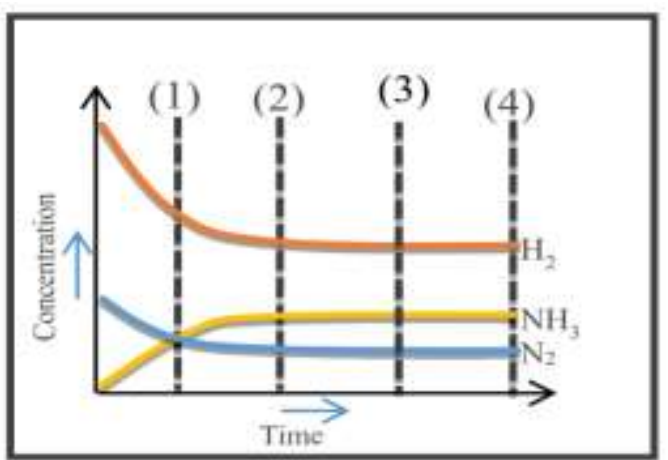

Picture 2: Scheme reaction in the reaction rates process

The cause of these misconceptions are the reason (reasoning) incomplete on the reaction of reversible or irreversible, stage of cognitive development of learners who are rarely trained to interact with graphics or illustrations, intuition is wrong and humanistic thoughts of the catalyst in the reaction rate, improper preconceptions in the discussion of temperatures (thermochemical). In interviews with the students discovered the fact that if the desire to learn a complicated graph is reduced, if the graph is regular one, then there is little curiosity, and if the graph is colourful then it would be more interesting. Learners see graph actually feel challenged, but if it is too complicated to make them lazy.

The description above indicates that learners actually want to learn something that is a bit tricky, if given the strategy in the presentation (color, shape, animation, etc) and guidance in the delivery of graphic information Tonder (2010). Therefore, if you want to familiarize learners then start to chart a rather simple (easy) first (certainly related to the discussion). If they are often see it and familiar, students can be introduced to chart a more complicated and not too underestimate learners so that they don't lose interest Hallenbeckand Wichowski (2004). Remember, this needs of the role of teachers for their guidance through guiding questions that can guide the construction of knowledge and not directly tell the meaning of the chart to be described (Suyono and Hariyanto, 2011).

Misconceptions that presented to students, "the catalyst facilitates the collision", this kind of thing can be avoided by giving an illustration that the catalyst to form intermediates with smaller $E_{a}$ is faster, there is no findint that the catalyst facilitates the collision, the catalyst will be back with the product but not yet certainly can be separated directly (therefore there is an homogeneous and heterogeneous catalysts). Media that can be used may include images, animations, movie, who would need to be careful in his election to the analogy in explaining the catalyst and certainly needs to be given boundaries.

The results of research Kolomuc and Tekin (2011) found a lot of failure in connecting various concepts are necessary to describe the reaction rate, as the rate of reaction and activation energy, more worrying, misconceptions like these are also found in the chemistry teacher. Saricayir et al. (2016) in their research did find that students tend to be weak in understanding chemical concepts and connecting one concept to another concept. Therefore, it is important to re-examine whether the knowledge that we have the appropriate form, especially for concepts that are often encountered that can be explained through scientific truth. Keep in mind that science develops, it does not mean the knowledge that has long been insignificant, but as the foundation stone for developing thinking owned. Thus, knowledge which we have of course need to be tested and examined its association with other fields of science so that it can be explained in a harmonious and air harmony despite having different viewpoints

Learners often fail when extracting information from a graph or picture, the evidence was got from many failures in the description of some discussion as reaction rate, reaction rate theory, the relationship with the equilibrium rate and enthalpy on the use of the catalyst. This shows that they rarely interact with the transformation of information, whereas graphic or image can facilitate the delivery of information. Based on the above, the skill (ability) this need to be trained, there is even information that can be conveyed through charts or images that can't be directly and well communicated through writing so that misconceptions learners can gradually be reduced.

Learners tend to lose their thinking guider. Therefore, the teacher's role is very important in the formation of knowledge to help the construction precisely through example to limit the concepts covered, create a habits that student often question why and how, the increased attention of learners by linking various concepts so that applications in life can be displayed, giving reward and punishment to motivate learners, use a persuasive approach to the media and to guide the construction of knowledge, and of course evaluating misconceptions or through summative evaluation of the type of questions Ormrod (2009). 
Evaluations are conducted to test the range of abilities (skills) rather narrow learners are not recommended, but rather evaluate arguments learners and learners thinking skills such as the ability for creativity LevyNahum et al. (2004). If learners can connect a wide range of concepts, the information storage will also be more robust and is expected to enter long-term memory through meaningful information and network thinking more.

The rate of reaction material consists of several concepts, such as understanding the reaction rate, the determination of the reaction rate, the rate law, and the factors that affect reaction rate, the explanation can be seen in Picture 3 below:

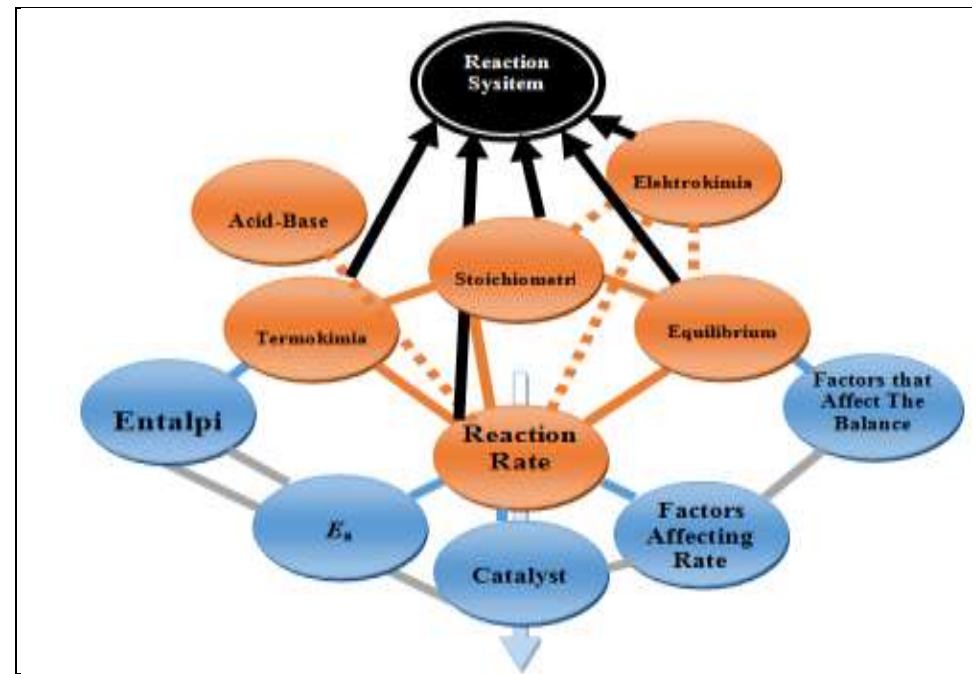

Picture 3: Illustration of the power of information with more connectors

The more the information is connected the more easily the information is maintained (difficult to hide from the idea in the form of forgetting), any discussion of training that will be connected to other subjects that can be sensed, according to the theory of meaningful learning Ormrod (2009). When students recall the information needed, the memory can be strengthened by the addition of keywords so that error reconstruction can be avoided and not inviting misconceptions in terms of constructivist learning. If some doubt happens, it can be checked by aligning alongside other relevant information, if deemed in line then the possibility of reconstruction (recall information) really Eggen and Kauchak (2012). Lastly, to further strengthen and motivate learners by giving gifts, punishment and reinforcement, according to the theory of behavior learning (Slavin, 2011).

Misconceptions can be avoided hopefully with effective teaching practices for content structured lessons. Based on captured material Rosenshine and Stevens in the Schunk et al. (2012), effective learning can be realized through: giving a brief overview prerequisite knowledge and interest; submit an explanation in a step-by-step, clear and detailed; provide active practicum and ask questions; guiding learners practice; provide systematic feedback and corrective instruction; provide explicit instruction and monitor the work of learners. Other studies have also shown that laboratory methods can develop a deeper understanding for the students on the material reaction rate than traditional learning (Demircioglu and Yadigaroglu, 2011).

\section{Conclusion}

Based on the research results can be summarized as follows: (1) Students experiencing misconceptions on the reaction rate, the definition of reaction rate is the number of reactions that take place per unit time; the reaction rate is constant because no additional concentration, temperature; high reaction rate at the beginning and then decreased because the reaction does not last long; zero order reaction means no reaction occurs; The equation is a rate of 2 (the "rate reductions" $\mathrm{N}_{2} \mathrm{O}_{5}$ ) = ("rate of increase" $\left.\mathrm{NO}_{2}\right)=4$ ("rate of increase" $\mathrm{O}_{2}$ ) is wrong; an exothermic reaction rate is faster because no need to be heated first ; the activation energy $(E a)=$ enthalpy; the concentration factor, pressure, and volume affect the rate of reaction in the reaction of the gas with the order to zero; volume addition of the reactants with the same concentration affect the rate of reaction; if some of the reaction compared to the speed, reaction with the highest temperature is the rate of the reaction; when the temperature is raised, the rate of the reaction towards products increased for all chemical reactions; catalysts accelerate the reaction rate and ease of collision.(2) Misconceptions experienced by learners are caused by preconception or early concept of learners, learners associative thinking, humanistic thinking, reasoning incomplete/wrong, intuition is wrong, the stage of cognitive development of learners, and learners'knowledge. 


\section{References}

[1] Ahiakwo, M, J and Isuguzo, C, Q. 2015. Students' Conceptions and Misconceptions in Chemical Kinetics in Port Harcourt Metropolis of Nigeria. African Journal of Chemical Education (AJOL). 5 (2). Hal 112-130.

[2] Barke, H.-D., Hazari, A., Yitbarek, S. 2009. Chapter 2Students' Misconceptions and How to Overcome Them. Misconception in Chemistry Addressing Perceptions in Chemical Educatio, 2009, IX, 294 p. Hardcover. http://www.springer.com/978-3-540-70988-

[3] Bilgin, IandGeban, O. 2006. The Effect of Cooperative Learning Approach Based on Conceptual Change Condition on Students' Understanding of Chemical Equilibrium Concepts. Journal of Science Education and Technology. Vol. 15, No. 1, DOI: 10.1007/s10956-006-0354-Z

[4] Cakmaci, G., Leach, J., Donnelly, J. 2006. Students' Ideas about Reaction Rate and it's Relationship with Concentration or Pressure. International Journal of Science Education. Vol. 28., No. 15., Hal. 1795-18.15. Routledge Publisher. Doi: 10.1080/09500690600823490

[5] Demircioglu, G and Yadigaroglu, M. 2011. The Effect of Laboratory Method on High School Students' Understanding of the Reaction Rate. Western Anatolia Journal of Educational Sciences (WAJES). Dokuz Eylul University Institute, Izmir, Turkey ISSN 1308-8971.

[6] Eggen, P and Kauchak, D. 2012. Strategi dan Model Pembelajaran. Indeks, Jakarta

[7] Fahmi. 2015. Miskonsepsi Siswa SMA Negeri Banjarmasin pada Materi Ikatan Kimia. Jurnal Pendidikan. Jilid. 4, Nomor, 2. Hal. 534-545. LPMP. Kalimantan Selatan

[8] Fraenkel, J, R., Wallen, N, E.,Hyun, H, H. 2013. How to Design and Evaluate Research in Education. McGraw-Hill, New York.

[9] Hallenbeck, K and Wichowski, C, P. 2004. A PSSA Guidebook for: Educators Students Parents. The Temple University Center for Professional Development in Career and Technical Education, Pennsylvania.

[10] Kariper, I, A. 2014. Misconceptions About Between Physical and Chemical Changing of Matters of Primary School Students. European J of Physics Education (EJPE). Volume 5, Issue 2.

[11] Kaya, E and Geban, O. 2012. Facilitating Conceptual Change in Rate of Reaction Concepts Using Conceptual Change Oriented Instruction. Education and Science Middle East Technical University. Vol. 37, No 163.

[12] Kolomuc, Aand Tekin, S. 2011. Chemistry Teachers' Misconceptions Concerning Concept of Chemical Reaction Rate. Eurasian J. Phys. Chem. Educ. 3(2): 84-101.

[13] LevyNahum, T., Hofstein, A., Mamlok-Naaman, R., Bar-Dov, Z. 2004. Can Final Examinations Amplify Students' Misconception in Chemistry? Chemistry Education: Research and Practice. Vol. 5, No. 3.

[14] Nazar, M., Sulastri, S., Winarni, R., Fitriana. 2010. Identifikasi Miskonsepsi Siswa SMA Pada Konsep Faktor-faktor yang Mempengaruhi Laju Reaksi. Jurnal Biologi Edukasi Program Studi Pendidikan Biologi FKIP Unsyiah. Vol. 2 , No. 2.

[15] Ormrod, J. E. 2009. Psikologi Pendidikan. Jilid 1:Membantu Siswa Tumbuh dan Berkembang. Terjemahan Wahyu Indianti dkk. Erlangga, Jakarta.

[16] Salirawati, D. 2010.Pengembangan ModelInstrumen PendeteksiMiskonsepsi Kimia padaPesertaDidik SMA.DisertasiDoktor.Program Pascasarjana Universitas Negeri Yogyakarta, Yogyakarta.

[17] Saricayir, H., Ay, S., Comek, A., Cansiz, G., Uce, M. 2016. Determining Students' Conceptual Understanding Level ofThermodynamics. Journal of Education and Training Studies. Vol. 4, No. 6. Published by Redfame Publishing. http://jets.redfame.com

[18] Schmitz, G. 2005. What Is a Reaction Race?. Journal of Chemical Education. Vol. 82., No. 7., Research: Science and Education. www.JCE.DivCHED.org

[19] Schunk, D, H., Pintrich, P, R., Meece, J, L. 2012. Motivasi dalam Pendidikan Teori, Penelitian, dan Aplikasi. Terjemahan Ellys Tjo. Indeks, Jakarta

[20] Slavin, R, E. 2011. Teori Pendidikan Teori dan Praktik. Terjemahan Marianto Samosir. Indeks, Jakarta.

[21] Sozbilir, M., Pinarbasi, T., Canpolat, N. 2010. Prospective Chemistry Teachers'Conceptions of Chemical Thermodynamics and Kinetics. Eurasia Journal of Mathematics, Science \& Technology Education. 6(2)., Hal. 111-120.

[22] Suyanti, R, D. 2010. Strategi Pembelajaran Kimia. Graha Ilmu, Yogyakarta.

[23] Suyono and Hariyanto. 2011. Belajar dan Pembelajaran Teori dan Konsep Dasar. Rosdakarya, Bandung.

[24] Tastan, O and Boz, Y. 2008. Effect of Cooperative Learning on Students Understanding of Reaction Rate. $9^{\text {th }}$ European Conference on Research in Chemical Education (ECRICE), Istanbul, Temmuz. Cukurova University \& Middle East Technical University, Turkey. 6-9.

[25] Taylor, A, K and Kowalski, P. 2012. Students' misconceptions in psychology: How you ask matters...sometimes. Journal of The Scholarship of Teaching and Learning. Vol. 12, No. 3, September 2012, pp. 62-72.

[26] Tonder, A, V. 2010. Difficulties in the Comprehension and Interpretation of a Selection of Graph Types and Subject-Specific Graphs Displayed by Senior Undergraduate Biochemistry Students in a South African University. Dissertation. Mathematics, Science and Technology Education, University of South Africa.

[27] Turanyi, T and Toth, Z. 2013. Hungarian University Students' Misunderstandings in Thermodynamics and Chemical Kinetics. This Journal is RSC Publishing, Chemistry Education Research and Practice. Vol 14, 105-116. 